\title{
Retrospective analysis of immediate in-brace correction of scoliosis attainable in patients with AIS: a SOSORT initiative
}

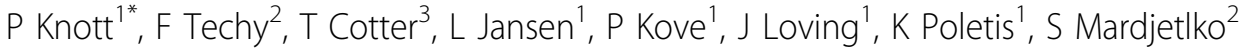 \\ From 9th International Conference on Conservative Management of Spinal Deformities - SOSORT 2012 \\ Annual Meeting \\ Milan, Italy. 10-12 May 2012
}

\section{Background}

The effectiveness of bracing in AIS has been debated for years, and there are few studies that can provide a clear picture of how a brace influences curve magnitude, rate of progression, or reduction in surgery. A 2007 review article found no clear advantage to bracing, over observation, in reducing the need for surgery [1]. However, the article highlighted the lack of uniformity in the studies it reviewed, and the high variability in the outcomes that it pooled. A 2010 Cochrane Systematic Review also found that there was only low-quality evidence in favor of using braces [2]. One must first be able to distinguish effective from ineffective bracing, as there is no reason to evaluate the outcome of ineffective braces. A standard must be set as to the amount of immediate curve correction that a brace should deliver, before any brace treatment is labeled as effective or ineffective. Other authors have outlined the appropriate criteria for evaluating brace effectiveness, but have not included immediate in-brace correction of the curve in their list of outcome measures [3]. This study was developed as a SOSORT board initiative, and will attempt to develop that standard.

\section{Aim}

The aim of this study is to evaluate the radiographs of patients who have just had a brace applied, and to determine the amount of correction that is routinely achieved.

\section{Methods}

For this study, a group of European physicians, skilled at scoliosis bracing, were recruited to submit sequential

'Rosalind Franklin University, Chicago, IL, USA

Full list of author information is available at the end of the article pre- and post-bracing radiographs of their patients for a specified period of time. American physicians, experienced in scoliosis evaluation, measured the Cobb angles in the two sets of radiographs. The percent correction was calculated using these two measurements.

\section{Results}

The results were stratified according to age, gender, initial curve magnitude, and brace type. Average curve corrections were calculated for each group.

\section{Conclusions}

Although there is variation among the subgroups evaluated, an effective brace should be able to achieve $50 \%$ correction of the curve magnitude, immediately after application. Research that includes patients whose curves has significantly less than $50 \%$ correction inbrace are not studies of "effective" bracing.

\section{Acknowledgements}

The authors would like to thank the following European medical centers that contributed the data for this study: Italian Scientific Spine Institute (ISICO), Sabrina Donzelli MD, Stefano Negrini MD, and Fabio Zaina MD; Bambino Gesu Childrens Hospital, Angelo Aulisa MD; Catholic University of the Sacred Hart, Lorenzo Aulisa MD; Tzanio General Hospital, Theodoros Grivas MD; Clinique du Parc, Jean Claude DeMauroy MD; University of Medical Sciences, Poznan, Poland, Tomasz Kotwicki, MD, PhD.

\section{Author details}

${ }^{1}$ Rosalind Franklin University, Chicago, IL, USA. ${ }^{2}$ Illinois Bone and Joint Institute, Chicago, IL, USA. ${ }^{3} 3$ T Imaging.

Published: 3 June 2013

\section{References}

1. Dolan LA, Weinstein SL: Surgical rates after observation and bracing for adolescent idiopathic scoliosis: an evidence-based review. Spine 2007, 32(19 Suppl):S91-S100. 
2. Negrini S, Minozzi S, Bettany-Saltikov J, Zaina F, Chockalingam N, Grivas TB, Kotwicki T, Maruyama T, Romano M, Vasiliadis ES: Braces for idiopathic scoliosis in adolescents. Cochrane Database Syst Rev 2010, 1: CD006850

3. Richards BS, Bernstein RM, D'Amato CR, Thompson GH: Standardization of criteria for adolescent idiopathic scoliosis brace studies: SRS Committee on Bracing and Nonoperative Management. Spine 2005, 30(18):2068-2075, discussion 2076-2067.

doi:10.1186/1748-7161-8-S1-049

Cite this article as: Knott et al:: Retrospective analysis of immediate inbrace correction of scoliosis attainable in patients with AIS: a SOSORT initiative. Scoliosis 2013 8(Suppl 1):049.

Submit your next manuscript to BioMed Central and take full advantage of:

- Convenient online submission

- Thorough peer review

- No space constraints or color figure charges

- Immediate publication on acceptance

- Inclusion in PubMed, CAS, Scopus and Google Scholar

- Research which is freely available for redistribution

Submit your manuscript at www.biomedcentral.com/submit
C) Biomed Central 